\title{
Ideal Cardiovascular Health Behaviours in Nationally Representative School-Based Samples of Adolescents in the Caribbean
}

\author{
Supa Pengpid (iD) 1,2 \\ Karl Peltzer $\mathbb{D}^{3}$
}

'ASEAN Institute for Health Development, Mahidol University, Salaya, Nakhon Pathom, Thailand; ${ }^{2}$ Department of Research Administration and Development, University of Limpopo, Turfloop, South Africa; ${ }^{3}$ Department of Psychology, University of the Free State, Bloemfontein, South Africa
Correspondence: Karl Peltzer Department of Psychology, University of the Free State, Bloemfontein, South Africa

Email kfpeltzer@gmail.com
Background: Ideal cardiovascular health behaviour (CVHB) measures four ideal health behaviours (non-smoking, body mass index $<85$ th Percentile, healthy diet, and physical activity). This study aimed to determine the prevalence, distribution, and correlates of ideal CVHB among adolescents in the Caribbean.

Methods: Nationally representative cross-sectional data of 2016 or 2017 with complete CVHB measurements were analysed from 7556 school adolescents from four Caribbean countries.

Results: The prevalence of 0-1 ideal metrics CVHB was 20.4\%, 2 ideal metrics $48.7 \%$, and 3-4 ideal metrics $30.8 \%$. Only $5.0 \%$ had all 4 ideal CVHB metrics, $41.0 \%$ intermediate CVH ( $\geq 1$ metric in the intermediate category and none in the poor category), and $54.0 \%$ had poor $\mathrm{CVH}$ ( $\geq 1$ metric in poor category). In adjusted logistic regression analysis, compared to students from Dominican Republic, students from Jamaica (Adjusted Odds Ratio-AOR: 1.36, 95\% confidence interval-CI: 1.01-1.85), students from Trinidad and Tobago (AOR: 1.46, 95\% CI: 1.17-1.82) and male sex (AOR: 1.35 , 95\% CI: 1.11-1.64) were positively associated with meeting 3-4 ideal CVHB metrics. In addition, in unadjusted analysis, rarely or sometimes experiencing hunger was negatively and high peer and parent support were positively associated with meeting $3-4$ ideal CVHB metrics.

Conclusion: The proportion of meeting 3-4 ideal CVHB metrics was low among adolescents in four Caribbean countries. Both high-risk and school-wide intervention programmes should be implemented in aiding to improve CVHB in Caribbean countries. Several factors associated with ideal CVHB were identified, which can be targeted in school health interventions.

Keywords: cardiovascular health behaviour, adolescents, Caribbean

\section{Background}

Globally, $31 \%$ of all global death were attributed to cardiovascular diseases (CVDs) in 2016. ${ }^{1}$ Stroke and ischaemic heart disease were the top-ranked causes of disability-adjusted life years (DALYs) in older adults in $2019 .^{2}$ More than threequarters of deaths from CVDs occur in low- and middle-income countries. ${ }^{1}$ To reduce CVDs, the American Heart Association (AHA) developed the concept of ideal cardiovascular health $(\mathrm{CVH})$ for adolescents and adults, including four ideal health behaviours and three health factors. ${ }^{3,4}$ An increasing number of ideal $\mathrm{CVH}$ metrics have been found protective against morbidity and mortality. ${ }^{5,6}$ Recently, more evidence has shown that ideal $\mathrm{CVH}$ behaviours (CVHB) in adolescents are 
associated with better cardiovascular outcomes in adulthood. $^{7-9}$ Caribbean countries lack national data on CVHB in the young population. A large proportion of mortality in the Caribbean countries can be attributed to heart disease (13-25\%) and cerebrovascular disease $(1-13 \%)^{10}$

In low- and middle-income countries, few studies reported on CVHB among adolescents, eg, in adolescents (12-18 years) in Beijing in 2014, China, 34.7\% had CVHB (3-4 ideal metrics), ${ }^{11}$ and among urban Chinese children and adolescents (6-18 years), 0.9\% had all four ideal CVHB, and 3-4 ideal CVHB16.4\% and 23.1\% (0-1) ideal CVHB. ${ }^{12}$ Studies in high-income countries found among Canadian adolescents (12-19 years) in 2009/10 a mean of $2.49 \mathrm{CVHB}, 49.7 \%$ poor CVHB (0-2 ideal metrics), 33.7\% intermediate CVHB (3 ideal metrics) and $16.6 \%$ ideal CVHB (4 ideal metrics), ${ }^{13}$ and in urban adolescents (12-19 years) in Philadelphia, USA, 0.6\% had ideal CVHB, 49.2\% intermediate CVHB (at least one intermediate and none in poor category) and 50.2\% poor CVHB (at least one poor category) the mean CVHB score was $2.50 .^{14}$ In a review of six studies (in the USA and Europe) among young people, Pacor et $\mathrm{al}^{15}$ found that the prevalence of ideal diet was $0-10 \%$, ideal physical activity (PA) ranged from $66.2 \%$ to $85.4 \%$ ideal body mass index (BMI) ranged from $66.3 \%$ to $85.4 \%$. In a study among adolescents (14-19 years) in Austria, ideal BMI 78.3\%, ideal PA 42.55, non-smoking 70.4\%, and ideal diet $8.1 \%,{ }^{16}$ and the prevalence of ideal $\mathrm{CVH}$ in European adolescents in 10 larger European cities (12.5-17.5 years) were ideal BMI $67.8 \%$, non-smoking $60.9 \%$, ideal PA $62.1 \%$, ideal diet $1.7 \% .^{17}$

Factors associated with CVHB among adolescents include younger adolescents, ${ }^{16}$ female sex, ${ }^{11,18}$ higher socioeconomic status, ${ }^{11}$ urban residence, ${ }^{18}$ parental ideal health behaviours, ${ }^{19}$ and better health-related quality of life. $^{20}$ This study aimed to determine the prevalence, distribution, and correlates of ideal CVHB among schoolgoing adolescents in four Caribbean countries in 2016/ 2017.

\section{Method}

\section{Participants and Procedures}

Data from four cross-sectional, nationally representative school-based student health surveys in four Caribbean countries in 2016-2017 were analyzed. ${ }^{21}$ These four countries were selected based on the latest available Global
School-based Student Health Surveys (GSHS) conducted in the Caribbean. More detailed information on the sampling and the data can be publicly accessed. ${ }^{21}$ The inclusion criteria for the present study were individuals from Trinidad and Tobago, Jamaica, Suriname, and Dominican Republic, with no data missing for smoking status, body mass index (BMI), physical activity (PA), and diet. From 9143 participants, a total of 7756 participants with full required information were included. National ethics committees approved the study and "written informed consent was obtained from the participating schools, parents, and students.". 21

\section{Measures}

\section{Cardiovascular Health Behaviour}

Poor, intermediate, and ideal CVHB levels for smoking, BMI, PA, and diet were determined based on the AHA definitions. ${ }^{3,4,22}$

\section{Smoking Status}

Poor smoking: Smoked in the past 30 days and ideal smoking: never tried.

\section{Body Mass Index (BMI)}

Poor BMI: >95th Percentile, Intermediate: 85th-95th Percentile, and ideal: $<85$ th Percentile. BMI was assessed by self-reported body weight and height.

\section{Healthy Diet}

Three indicators of healthy diet were assessed: 1) ideal fruit and vegetable intake: $\geq 5$ servings/day; 2) ideal soft drink intake: less than daily soft drink intake; and 3) ideal fast-food intake per week: $\leq 1$ day per week. Students who scored 2 or 3 healthy diet components: ideal, students with one component as intermediate and students with 0 components as having a poor healthy diet metric. ${ }^{4,22}$

\section{Physical Activity (PA)}

"Poor: None, Intermediate: $>0$ and $<60$ min of moderate or vigorous PA every day, and Ideal: $\geq 60$ min of moderate or vigorous PA every day."

The four CVHB items were dichotomised (1: ideal, 0: not ideal), and grouped into 0-1, 2, and 3-4 ideal CVHB metrics. ${ }^{11}$ In addition, three CVHB groups were created as follows:

ideal CVHB is all four metrics at ideal level, intermediate CVHB is at least one health metric at the intermediate level, but no poor CVHB metrics, and poor CVHB is at least one of the four CVHB metrics at poor level. ${ }^{3,4,14}$ 
Sociodemographic covariates included age, sex, proxy of economic status (experience of hunger), peer support, school attendance, parental support, and psychological distress. $^{21}$ Peer support was sourced from the question "During the past 30 days, how often were most of the students in your school kind and helpful?" Responses were trichotomized into 1: Never or Rarely, 2: Sometimes and 3: Most of the time or Always. ${ }^{21}$ The psychological distress items (no close friends, loneliness, anxiety, suicidal ideation, and suicide attempt) were summed and grouped into $0=0,1=1$ single, and $2-5=2$ multiple. ${ }^{23}$ "The four items on parental or guardian support were summed and classified into three groups, 0-1 low, 2 medium, and 3-4 high support". 23

\section{Data Analysis}

Considering the clustered study design, all statistical analyses were conducted with STATA software version 14.0 (Stata Corporation, College Station, TX, USA). Only participants with complete CVHB assessments were included in the analysis. Chi-square tests were used for estimating differences in proportions and Student's $t$-test for differences in means. CVHB metrics are described across ideal, intermediate, and poor CVH. Unadjusted and adjusted logistic regressions were used to calculate sociodemographic predictors of meeting 3-4 CVHB metrics. Variables adjusted for included study country, sex, age group, experience of hunger (proxy for socioeconomic status), psychological distress, school attendance, parental, and peer support. P-values below 0.05 were accepted as significant and missing values were excluded from the analysis.

\section{Results}

\section{Sample Characteristics}

The sample included 7756 school adolescents (15 years: median age, IQR: $13-16$ ), 54.2\% were female, and 58.3\% had high socioeconomic status (never experienced hunger). The prevalence of $0-1$ ideal CVHB metrics was 20.4\%, 2 ideal metrics $48.7 \%$, and 3-4 ideal CVHB $30.8 \%$ (see Table 1).

\section{Distribution of CVHB Metrics}

The distribution of the three levels of all four CVHB metrics in the overall adolescent population and by country and sex is shown in Table 2. A significant higher proportion of girls had ideal smoking than boys, while boys had significantly higher ideal BMI, PA, and ideal diet.

In all, $1.5 \%$ had zero, $19.0 \%$ one, $48.7 \%$ two, $25.9 \%$ three, and $5.0 \%$ all four ideal CVHB metrics. In addition, $41.0 \%$ had intermediate $\mathrm{CVH}$ ( $\geq 1$ metric in the intermediate category and none in the poor category), and $54.0 \%$ had poor $\mathrm{CVH}$ ( $\geq 1$ metric in poor category). The total mean number of ideal CVHB metrics was 2.14 $(\mathrm{SD}=0.8)$. Boys had higher ideal CVHB metrics in the different measures than girls (see Table 2).

\section{Associations with Meeting 3-4 Ideal CVHB Metrics}

In adjusted logistic regression analysis, compared to students from Dominican Republic, students from Jamaica (adjusted odds ratio - AOR: 1.36, 95\% confidence interval - CI: 1.01-1.85), students from Trinidad and Tobago (AOR: 1.46, 95\% CI: 1.17-1.82) and male sex (AOR: $1.35,95 \% \mathrm{CI}: 1.11-1.64)$ were positively associated with meeting 3-4 ideal CVHB metrics. In addition, in the unadjusted analysis, rarely or sometime experiencing hunger was negatively and high peer and parent support were positively associated with meeting 3-4 ideal CVHB metrics (see Table 3).

\section{Discussion}

To our knowledge, this is the first national study among adolescents on the prevalence and distribution of CVHB metrics in the Caribbean. In this nationally representative sample of adolescents in four Caribbean countries, the prevalence of poor CVHB (0-1 ideal metrics) (20.4\%), and ideal CVHB (3-4 ideal metrics) (30.8\%), was similar to a study among adolescents (12-18 years) in Beijing (34.7\% 3-4 ideal CVHB metrics), ${ }^{11}$ but higher than in urban Chinese children and adolescents (6-18 years) (23.1\% 0-1 ideal CVHB and 16.4\% 3-4 ideal CVHB). ${ }^{12}$ The prevalence of having all four ideal CVHBs in this study $(5.0 \%)$ was higher than in urban Chinese children and adolescents (6-18 years) $(0.9 \%),{ }^{12}$ and in urban adolescents (12-19 years) in Philadelphia, USA (0.6\%), ${ }^{14}$ but lower than among Canadian adolescents (12-19 years) $(16.6 \%) .{ }^{13}$ The prevalence of intermediate $\mathrm{CVH} \quad(\geq 1$ metric in the intermediate category and none in the poor category) $(41.0 \%)$, and poor $\mathrm{CVH}$ ( $\geq 1$ metric in poor category) $(54.0 \%)$ was similar to adolescents in Philadelphia (49.2\% intermediate CVHB and 50.2\% poor CVHB). ${ }^{14}$ The total mean CVHB (2.14) in this study was 
Table I Sample and Cardiovascular Health Behaviour (CVHB) Among School Adolescents in Four Caribbean Countries, 2016-2017

\begin{tabular}{|c|c|c|c|c|}
\hline \multirow[t]{2}{*}{ Variables } & Sample & 0-I Ideal CVHB & 2 CVHB & 3-4 Ideal CVHB \\
\hline & $\mathbf{N}(\%)$ & $\%$ & $\%$ & $\%$ \\
\hline All & 7756 & 20.4 & 48.7 & 30.8 \\
\hline \multicolumn{5}{|l|}{ Country } \\
\hline Dominican Republic & II $23(14.5)$ & 20.5 & 51.1 & 28.4 \\
\hline Jamaica & I 460 (I8.8) & 20.4 & 45.6 & 34.0 \\
\hline Suriname & $1979(25.5)$ & 21.9 & 47.5 & 30.6 \\
\hline Trinidad and Tobago & $3194(4 I .2)$ & 19.7 & 44.1 & 36.2 \\
\hline \multicolumn{5}{|l|}{ Sex } \\
\hline Female & $4207(54.2)$ & 22.3 & 49.6 & 28.1 \\
\hline Male & $3549(45.8)$ & 18.5 & 47.8 & 33.8 \\
\hline \multicolumn{5}{|l|}{ Age in years } \\
\hline 13 or less & $2020(12.9)$ & 20.4 & 47.5 & 32.0 \\
\hline $14-15$ & $3452(42.5)$ & 20.4 & 49.6 & 30.0 \\
\hline 16 or more & $2284(44.7)$ & 20.5 & 48.2 & 31.4 \\
\hline \multicolumn{5}{|l|}{ Hungry } \\
\hline Never & $4146(58.3)$ & 19.4 & 49.1 & 31.5 \\
\hline Rarely/sometimes & $2982(37.2)$ & 22.1 & 48.5 & 29.5 \\
\hline Mostly/always & $587(4.5)$ & 18.7 & 45.8 & 35.5 \\
\hline \multicolumn{5}{|l|}{ Psychological distress } \\
\hline 0 & 4377 (6I.8) & 18.3 & 50.0 & 31.7 \\
\hline I & $1530(19.3)$ & 18.8 & 46.3 & 34.9 \\
\hline $2-5$ & I 408 (I8.9) & 26.1 & 46.8 & 27.1 \\
\hline \multicolumn{5}{|c|}{ School attendance past 30 days } \\
\hline Not all days & $1686(25.5)$ & 25.5 & 45.8 & 28.7 \\
\hline All days & $5956(74.5)$ & 18.5 & 49.9 & 31.6 \\
\hline \multicolumn{5}{|l|}{ Peer support } \\
\hline Never/rarely & $2534(30.2)$ & 24.8 & 44.1 & 31.2 \\
\hline Sometimes & $234 \mid(29.3)$ & 19.6 & 50.8 & 29.6 \\
\hline Mostly/always & $2691(40.5)$ & 17.8 & 50.4 & 31.8 \\
\hline \multicolumn{5}{|l|}{ Parental support } \\
\hline Low $(0-1)$ & $3047(37.8)$ & 22.5 & 46.6 & 31.1 \\
\hline Medium (2) & $1966(28.0)$ & 19.3 & 48.6 & 32.1 \\
\hline High (3-4) & $2219(34.1)$ & 17.7 & 52.2 & 30.1 \\
\hline
\end{tabular}

Abbreviation: CVHB, cardiovascular health behaviour.

lower than among Canadian adolescents $(2.49)^{13}$ and adolescents in Philadelphia (2.50). ${ }^{14}$

Similar to a review of six studies (in the USA and Europe), ${ }^{15}$ this study found that a healthy diet had a low prevalence among ideal CVHB metrics (32.4\%), which is, however, higher than in a review of six studies (iin the USA and Europe) $(0-10 \%) .{ }^{15}$ Some of these differences may be explained by the stricter AHA definitions, eg, on diet (scoring 4 or 5 healthy diet components, compared to 2 or 3 healthy diet components in this study), in the six studies compared to this study. ${ }^{22}$ The highest ideal CVHB metric was found for non-smoking $(89.7 \%)$, which is higher than in European adolescents in 10 larger European cities (12.5-17.5 years) $(60.9 \%)^{17}$ and among adolescents in Austria (70.4\%). ${ }^{16}$ Ideal BMI (66.6\%) in this study was similar to the 10 larger European cities study $(67.8 \%)^{17}$ and lower than among adolescents in Austria $(78.3 \%)^{16}$ and ideal PA (15.8\%) was much lower than in the 10 European cities study $(62.1 \%)^{17}$ and among Austrian adolescents $(42.6 \%) .{ }^{16}$ The low prevalence of 
Table 2 Ideal Cardiovascular Health Behaviour (CVHB) Metrics Distribution

\begin{tabular}{|c|c|c|c|c|c|c|c|c|c|}
\hline \multirow[t]{2}{*}{ Health Metrics } & & $\begin{array}{l}\text { Total } \\
\text { Sample }\end{array}$ & $\begin{array}{l}\text { Dominican } \\
\text { Republic }\end{array}$ & Jamaica & Suriname & $\begin{array}{l}\text { Trinidad and } \\
\text { Tobago }\end{array}$ & Boys & Girls & \multirow[t]{2}{*}{$\begin{array}{l}\text { Chi-Square } \\
p \text {-value }\end{array}$} \\
\hline & & $\%$ & $\%$ & $\%$ & $\%$ & $\%$ & $\%$ & $\%$ & \\
\hline Smoking & $\begin{array}{l}\text { Poor } \\
\text { Intermediate } \\
\text { Ideal }\end{array}$ & $\begin{array}{l}10.3 \\
- \\
89.7\end{array}$ & $\frac{8.3}{-}$ & $\begin{array}{l}14.7 \\
- \\
85.3\end{array}$ & $\begin{array}{l}13.7 \\
- \\
86.3\end{array}$ & $\begin{array}{l}10.4 \\
- \\
89.6\end{array}$ & $\begin{array}{l}12.5 \\
- \\
87.5\end{array}$ & $\begin{array}{l}7.9 \\
- \\
92.1\end{array}$ & $<0.001$ \\
\hline Body mass index & $\begin{array}{l}\text { Poor } \\
\text { Intermediate } \\
\text { Ideal }\end{array}$ & $\begin{array}{l}10.8 \\
16.6 \\
66.6\end{array}$ & $\begin{array}{l}10.3 \\
17.7 \\
72.0\end{array}$ & $\begin{array}{l}9.3 \\
14.3 \\
76.4\end{array}$ & $\begin{array}{l}11.2 \\
16.8 \\
72.0\end{array}$ & $\begin{array}{l}16.7 \\
16.6 \\
66.6\end{array}$ & $\begin{array}{l}9.0 \\
15.2 \\
75.7\end{array}$ & $\begin{array}{l}12.5 \\
18.0 \\
69.5\end{array}$ & $<0.001$ \\
\hline Diet & $\begin{array}{l}\text { Poor } \\
\text { Intermediate } \\
\text { Ideal }\end{array}$ & $\begin{array}{l}15.3 \\
52.3 \\
32.4\end{array}$ & $\begin{array}{l}12.3 \\
57.1 \\
30.6\end{array}$ & $\begin{array}{l}20.0 \\
47.6 \\
32.4\end{array}$ & $\begin{array}{l}20.3 \\
46.3 \\
33.3\end{array}$ & $\begin{array}{l}20.8 \\
35.8 \\
43.5\end{array}$ & $\begin{array}{l}14.6 \\
51.6 \\
33.8\end{array}$ & $\begin{array}{l}15.9 \\
52.7 \\
31.4\end{array}$ & 0.007 \\
\hline \multicolumn{2}{|c|}{ Ideal fruit and vegetable } & 17.9 & 17.4 & 17.3 & 29.7 & 16.9 & 17.7 & 18.1 & 0.952 \\
\hline \multicolumn{2}{|l|}{ Ideal soft drinks } & 29.4 & 25.4 & 32.2 & 20.6 & 47.9 & 31.0 & 27.8 & 0.890 \\
\hline \multicolumn{2}{|l|}{ Ideal fast food } & 73.8 & 79.5 & 66.5 & 66.6 & 64.2 & 75.3 & 72.3 & 0.002 \\
\hline Physical activity & $\begin{array}{l}\text { Poor } \\
\text { Intermediate } \\
\text { Ideal }\end{array}$ & $\begin{array}{l}32.0 \\
52.2 \\
15.8\end{array}$ & $\begin{array}{l}33.7 \\
54.3 \\
12.0\end{array}$ & $\begin{array}{l}29.1 \\
47.3 \\
23.6\end{array}$ & $\begin{array}{l}34.5 \\
46.6 \\
18.8\end{array}$ & $\begin{array}{l}27.2 \\
52.6 \\
20.2\end{array}$ & $\begin{array}{l}28.3 \\
53.5 \\
18.1\end{array}$ & $\begin{array}{l}34.5 \\
51.3 \\
14.3\end{array}$ & $<0.001$ \\
\hline $\begin{array}{l}\text { Total number of } \\
\text { CVHB }\end{array}$ & $\begin{array}{l}0 \\
1 \\
2 \\
3 \\
4\end{array}$ & $\begin{array}{l}1.5 \\
19.0 \\
48.7 \\
25.9 \\
5.0\end{array}$ & $\begin{array}{l}1.3 \\
19.2 \\
51.1 \\
24.8 \\
3.6\end{array}$ & $\begin{array}{l}1.5 \\
18.9 \\
45.6 \\
26.2 \\
7.7\end{array}$ & $\begin{array}{l}3.1 \\
18.8 \\
47.5 \\
25.7 \\
4.9\end{array}$ & $\begin{array}{l}1.8 \\
18.0 \\
44.1 \\
30.6 \\
5.5\end{array}$ & $\begin{array}{l}1.2 \\
17.3 \\
47.8 \\
27.9 \\
5.9\end{array}$ & $\begin{array}{l}1.7 \\
20.6 \\
49.6 \\
23.9 \\
4.1\end{array}$ & $<0.001$ \\
\hline CVHB metrics & $\begin{array}{l}\text { Poor }^{\mathrm{a}} \\
\text { Intermediate }^{\mathrm{b}} \\
\text { Ideal }^{\mathrm{c}}\end{array}$ & $\begin{array}{l}54.0 \\
41.0 \\
5.0\end{array}$ & $\begin{array}{l}52.3 \\
44.1 \\
3.6\end{array}$ & $\begin{array}{l}44.1 \\
36.2 \\
7.7\end{array}$ & $\begin{array}{l}59.7 \\
35.4 \\
4.9\end{array}$ & $\begin{array}{l}56.1 \\
38.3 \\
5.5\end{array}$ & $\begin{array}{l}51.2 \\
42.9 \\
5.9\end{array}$ & $\begin{array}{l}56.7 \\
39.1 \\
4.1\end{array}$ & $<0.001$ \\
\hline \multirow{2}{*}{$\begin{array}{l}\text { Mean number } \\
\text { of CVHB }\end{array}$} & & $M(S D)$ & $M(S D)$ & $M(S D)$ & $M(S D)$ & $M(S D)$ & $M(S D)$ & $M(S D)$ & $t$-test \\
\hline & & $2.14(0.8)$ & $2.10(0.8)$ & $2.20(0.9)$ & $2.11(0.9)$ & $2.20(0.9)$ & $2.20(0.8)$ & $2.08(0.8)$ & $<0.001$ \\
\hline
\end{tabular}

Notes: a Poor CVHB (at least one poor category), 'Intermediate CVHB (at least one intermediate and none in poor category) and ${ }^{\mathrm{C} I d e a l} \mathrm{CVHB}$ (all 4 ideal metrics). ${ }^{3,4,14}$ Abbreviations: CVHB, cardiovascular health behaviour; M, mean; SD, standard deviation.

ideal PA (15.8\%) in this study compares with the weighted average among adolescents in 26 Latin American and Caribbean countries (15.5\% ideal PA) ${ }^{24}$ and the prevalence of ideal BMI (66.6\%) is lower weighted average among adolescents in 15 Latin American and Caribbean countries $\left(73.6 \%\right.$ ideal BMI). ${ }^{25}$

Consistent with previous research, ${ }^{15}$ ideal CVHB differed by country, with Dominican Republic having the lowest ideal CVHB. Unlike some studies in China, ${ }^{11,18}$ this study showed an association between male sex and ideal CVHB. The male sex preponderance of ideal CVHB may be particularly explained by their high proportion of ideal BMI, ideal PA and ideal diet compared to girls. Interventions targeting girls may be needed given lower CVHB shown, in particular in Trinidad and Tobago.

In unadjusted analysis, compared to never experiencing hunger, rarely or sometimes experiencing hunger was inversely associated with ideal CVHB. This finding is consistent with a study showing that higher socioeconomic status was associated with ideal CVHB. ${ }^{11}$ The study found in unadjusted analysis that high peer and parental support are positively associated with ideal CVHB, which seems to confirm results from some previous studies. ${ }^{19,26,27}$ Unlike some previous research, ${ }^{20}$ this 
Table 3 Associations with Meeting 3-4 Cardiovascular Health Behaviour (CVHB)

\begin{tabular}{|c|c|c|c|c|}
\hline Variables & COR $(95 \% \mathrm{Cl})$ & p-value & $\operatorname{AOR}(95 \% \mathrm{CI})^{\mathrm{a}}$ & p-value \\
\hline \multicolumn{5}{|l|}{ Country } \\
\hline Dominican Republic & I (Reference) & & I (Reference) & \\
\hline Jamaica & $2.30(1.70,3.10)$ & $<0.001$ & $1.36(1.01,1.85)$ & 0.046 \\
\hline Suriname & $1.63(1.20,2.23)$ & 0.002 & $1.06(0.88,1.28)$ & 0.520 \\
\hline Trinidad and Tobago & $\mathrm{I} .8 \mathrm{I}(\mathrm{I} .4 \mathrm{I}, 2.32)$ & $<0.001$ & $1.46(1.17,1.82)$ & $<0.001$ \\
\hline \multicolumn{5}{|l|}{ Sex } \\
\hline Female & I (Reference) & & I (Reference) & \\
\hline Male & $1.33(1.09,1.59)$ & 0.005 & $1.35(1.11,1.64)$ & 0.004 \\
\hline \multicolumn{5}{|l|}{ Age in years } \\
\hline 13 or less & I (Reference) & & I (Reference) & \\
\hline $14-15$ & $0.85(0.66,1.09)$ & 0.203 & $1.15(0.87,1.52)$ & 0.932 \\
\hline 16 or more & $0.89(0.37,2.11)$ & 0.783 & $1.06(0.84,1.34)$ & 0.613 \\
\hline \multicolumn{5}{|l|}{ Hungry } \\
\hline Never & I (Reference) & & I (Reference) & \\
\hline Rarely/sometimes & $0.7 \mid(0.53,0.95)$ & 0.020 & $0.88(0.63,1.23)$ & 0.449 \\
\hline Mostly/always & $0.74(0.50$, I. 10$)$ & 0.137 & $1.02(0.64,1.63)$ & 0.918 \\
\hline \multicolumn{5}{|l|}{ Psychological distress } \\
\hline 0 & I (Reference) & & I (Reference) & \\
\hline I & $1.12(0.87,1.43)$ & 0.371 & $1.08(0.80,1.48)$ & 0.601 \\
\hline $2-5$ & $0.80(0.61,1.05)$ & 0.103 & $0.97(0.70,1.34)$ & 0.865 \\
\hline \multicolumn{5}{|c|}{ School attendance past 30 days } \\
\hline Not all days & I (Reference) & & I (Reference) & \\
\hline All days & $1.28(0.95,1.72)$ & 0.107 & $1.12(0.82,1.54)$ & 0.469 \\
\hline \multicolumn{5}{|l|}{ Peer support } \\
\hline Never/rarely & I (Reference) & & I (Reference) & \\
\hline Sometimes & $0.97(0.74, \mathrm{I} .26)$ & 0.801 & $0.94(0.72,1.22)$ & 0.633 \\
\hline Mostly/always & $1.38(1.03,1.83)$ & 0.029 & $1.20(0.88,1.65)$ & 0.249 \\
\hline \multicolumn{5}{|l|}{ Parental support } \\
\hline Low $(0-1)$ & I (Reference) & & I (Reference) & \\
\hline Medium (2) & $1.02(0.72,1.46)$ & 0.907 & $0.98(0.68, I .41)$ & 0.896 \\
\hline High (3-4) & $1.38(1.03,1.85)$ & 0.032 & $\mathrm{I} .17(0.85, \mathrm{I} .6 \mathrm{I})$ & 0.345 \\
\hline
\end{tabular}

Notes: ${ }^{a}$ Adjusted for study country, sex, age group, experience of hunger (proxy for socioeconomic status), psychological distress, school attendance, parental and peer support.

Abbreviations: $\mathrm{COR}$, crude odds ratio; $\mathrm{AOR}$, adjusted odds ratio; $\mathrm{Cl}$, confidence interval.

study did not show any association between psychological well-being and ideal CVHB. To improve CVH among adolescents in the Caribbean, CVH behaviours should be improved through comprehensive interventions targeting the promotion of healthy diets, body weight control, smoking cessation, and PA. Findings of the study may help in the NCD policy and plan of action in the Caribbean. The Health and Family Life Education (HFLE) school health programme has been adapted by the educational ministers of Caribbean Community (CARICOM) states to be implemented through a school life skills approach, including content areas related to eating and fitness, self- and interpersonal relationships, sexuality and sexual health, and managing the environment. ${ }^{28}$ However, in an evaluation of HFLE implementation in Trinidad and Tobago found that in some cases only partial implementation and nonimplementation. ${ }^{29}$

The study strength is the large nationally representative sample and using standardized World Health Organization GSHS methodology and measures. Study limitations include the cross-sectional design, the 
assessment of some variables were assessed by selfreport. Furthermore, we included only three healthy diet components and not all five components of AHA healthy diet, and BMI was only assessed by self-reported body weight and height. Studies among adolescents comparing self-reported and measured body weight show that differences are relatively small, with estimates likely to be lower in self-report than measured body weight. $^{30,31}$ Furthermore, other behaviours such as sleep, its duration and quality, health care access, and neighborhood environmental factors that could impact cardiovascular health were not assessed and should be included in future studies.

\section{Conclusion}

The proportion of 3-4 ideal CVHB metrics was low among school going adolescents in four Caribbean countries. Both high-risk and school-wide intervention programmes should be implemented in aiding to improve $\mathrm{CVH}$ in the Caribbean. Several factors associated with ideal CVHB were identified, which can be targeted in school health interventions.

\section{Abbreviations}

AHA, American Heart Association; BP, blood pressure; BMI, body mass index; CVD, cardiovascular disease; $\mathrm{CVH}$, cardiovascular health; DALYs, disability adjusted life years; FV, fruit and vegetables; GSHS, Global Schoolbased Student Health Survey; HFLE, Health and Family Life Education (HFLE); NCD, non-communicable disease; PA, physical activity.

\section{Acknowledgment}

The data source, the World Health Organization NCD Microdata Repository (URL: https://extranet.who.int/ ncdsmicrodata/index.php/catalog), is hereby acknowledged.

\section{Funding}

There is no funding to report.

\section{Disclosure}

The authors report no conflicts of interest in this work.

\section{References}

1. World Health Organization (WHO). Cardiovascular diseases (CVDs); 2017. Available from: https://www.who.int/news-room/fact-sheets /detail/cardiovascular-diseases-(cvds). Accessed November 11, 2020.
2. GBD 2019 Diseases and Injuries Collaborators. Global burden of 369 diseases and injuries in 204 countries and territories, 1990-2019: a systematic analysis for the Global Burden of Disease Study 2019. Lancet. 2020;396(10258):1204-1222. doi:10.1016/S0140-6736(20) 30925-9.

3. Lloyd-Jones DM, Hong Y, Labarthe D, et al. Defining and setting national goals for cardiovascular health promotion and disease reduction: the American Heart Association's strategic Impact Goal through 2020 and beyond. Circulation. 2010;121(4):586-613. doi:10.1161/ CIRCULATIONAHA.109.192703

4. Huffman MD, Capewell S, Ning H, et al. Cardiovascular health behavior and health factor changes (1988-2008) and projections to 2020: results from the National Health and Nutrition Examination Surveys. Circulation. 2012;125:2595-2602. doi:10.1161/ CIRCULATIONAHA.111.070722

5. Younus A, Aneni EC, Spatz ES, et al. A systematic review of the prevalence and outcomes of ideal cardiovascular health in US and non-US populations. Mayo Clin Proc. 2016;91(5):649-670. doi:10.1016/j.mayocp.2016.01.019

6. Dong C, Rundek T, Wright CB, Anwar Z, Elkind MSV, Sacco RL. Ideal cardiovascular health predicts lower risks of myocardial infarction, stroke, and vascular death across whites, blacks and Hispanics: the Northern Manhattan Study. Circulation. 2012;125 (24):2975-2984. doi:10.1161/CIRCULATIONAHA.111.081083

7. Allen NB, Krefman AE, Labarthe D, et al. Cardiovascular health trajectories from childhood through middle age and their association with subclinical atherosclerosis. JAMA Cardiol. 2020;5(5):557-566. doi:10.1001/jamacardio.2020.0140

8. Laitinen TT, Pahkala K, Magnussen CG, et al. Ideal cardiovascular health in childhood and cardiometabolic outcomes in adulthood: the Cardiovascular Risk in Young Finns Study. Circulation. 2012;125 (16):1971-1978. doi:10.1161/CIRCULATIONAHA.111.073585

9. Gooding HC, Milliren C, Shay CM, Richmond TK, Field AE, Gillman MW. Achieving cardiovascular health in young adulthood-which adolescent factors matter? $J$ Adolesc Health. 2016;58(1):119-121. doi:10.1016/j.jadohealth.2015.09.011

10. Razzaghi H, Martin DN, Quesnel-Crooks S, et al. 10-year trends in noncommunicable disease mortality in the Caribbean region. Rev Panam Salud Publica. 2019;43:e37. doi:10.26633/RPSP.2019.37

11. Dong H, Yan Y, Liu J, et al. Alarming trends in ideal cardiovascular health among children and adolescents in Beijing, China, 2004 to 2014. Int J Cardiol. 2017;231:264-270. doi:10.1016/j.ijcard.2016.12.027

12. Yan Y, Liu J, Zhao X, et al.; China Child and Adolescent Cardiovascular Health $(\mathrm{CCACH})$ collaboration group. Cardiovascular health in urban Chinese children and adolescents. Ann Med. 2019;51(1):88-96. doi:10.1080/07853890.2019.1580383

13. Maclagan LC, Park J, Sanmartin C, et al. The CANHEART health index: a tool for monitoring the cardiovascular health of the Canadian population. CMAJ. 2014;186(3):180-187. doi:10.1503/cmaj.131358

14. Lenhart CM, Manjelievskaia J, Echeverri A, Patterson F. Cardiovascular health among Philadelphia adolescents: analysis of youth risk behaviour data, 2011. Cardiol Young. 2014;24(4):748-751. doi:10.1017/S1047951113001121

15. Pacor JM, Younus A, Malik R. Prevalence of ideal cardiovascular health metrics in children \& adolescents: a systematic review. Prog Pediatr Cardiol. 2016;43:141-146. doi:10.1016/j.ppedcard.20 16.09.002

16. Gande N, Pechlaner R, Bernar B, et al.; for the Early Vascular Aging (EVA) Study Group. Cardiovascular health behaviors and associations of sex, age, and education in adolescents - results from the EVA Tyrol Study. Nutr Metabol Cardiovasc Dis. 2020. doi:10.1016/j. numecd.2020.11.002

17. Henriksson P, Henriksson H, Gracia-Marco L, et al.; HELENA study group. Prevalence of ideal cardiovascular health in European adolescents: the HELENA study. Int $J$ Cardiol. 2017;240:428-432. doi:10.1016/j.ijcard.2017.03.022. 
18. Chen FF, Chang SY, Hou DQ, et al. [Characteristics of cardiovascular health of children and adolescents aged 6-16 years in Beijing during 2017-2018]. Zhonghua Yu Fang Yi Xue Za Zhi. 2018;52(11):1124-1129. Chinese. doi:10.3760/cma.j.issn.0253-9624.2018.11.006.

19. Komulainen K, Mittleman MA, Jokela M, et al. Socioeconomic position and intergenerational associations of ideal health behaviors. Eur J Prev Cardiol. 2019;26(15):1605-1612. doi:10.1177/2047487319850959

20. Agostinis-Sobrinho C, Werneck AO, Kievišienė J, et al. Ideal cardiovascular health status and health-related quality of life in adolescents: the LABMED physical activity study. Rev Paul Pediatr. 2021;39:e2019343. doi:10.1590/1984-0462/2021/39/2019343

21. World Health Organization (WHO). Global school-based student health survey (GSHS); 2019. Available from: https://www.who.int/ ncds/surveillance/gshs/en/. Accessed December 2, 2020.

22. Aatola H, Hutri-Kähönen N, Juonala M, et al. Prospective relationship of change in ideal cardiovascular health status and arterial stiffness: the Cardiovascular Risk in Young Finns Study. $J \mathrm{Am}$ Heart Assoc. 2014;3(2):e000532. doi:10.1161/JAHA.113.000532

23. Pengpid S, Peltzer K. Behavioral risk factors of non-communicable diseases among a nationally representative sample of school-going adolescents in Indonesia. Int $J$ Gen Med. 2019;12:387-394. doi:10.2147/IJGM.S226633

24. Aguilar-Farias N, Martino-Fuentealba P, Carcamo-Oyarzun J, et al. A regional vision of physical activity, sedentary behaviour and physical education in adolescents from Latin America and the Caribbean: results from 26 countries. Int J Epidemiol. 2018;47(3):976-986. doi:10.1093/ije/dyy033

25. Caleyachetty R, Thomas GN, Kengne AP, et al. The double burden of malnutrition among adolescents: analysis of data from the Global School-Based Student Health and Health Behavior in School-Aged Children surveys in 57 low- and middle-income countries. Am J Clin Nutr. 2018;108(2):414-424. doi:10.1093/ajcn/nqy105
26. Pengpid S, Peltzer K. Parental involvement and health risk behaviours among school-going adolescents in six African countries. J Psychol Afr. 2018;28(3):212-217. doi:10.1080/14330237.2017.1409481

27. Pengpid S, Peltzer K. Parental involvement, health behaviours and mental health among school-going adolescents in six Asian countries. Chiang Mai Univ J Soc Sci Hum. 2016;3(2):115-132. doi:10.12982/ CMUJASR.2016.0007

28. Republic of Trinidad and Tobago Ministry of Education Curriculum Development Division. Primary Health and Family Life Education (H.F.L.E.) curriculum; 2006. Available from: https://www.moe.gov.tt/ wp-content/uploads/2019/06/Primary-HFLE-Curriculum.pdf. Accessed February 10, 2021.

29. Onuoha CA, Dyer-Regis B, Onuoha PC. Implementation levels of a life-skill based school health program in a Caribbean country. Int J Health Sci Res. 2017;7(4):353-359.

30. Koebnick C, Saksvig B, Li X, Sidell M, Wu TT, Young DR. The accuracy of self-reported body weight is high but dependent on recent weight change and negative affect in teenage girls. Int J Environ Res Public Health. 2020;17(21):8203. doi:10.3390/ijerph17218203

31. Pérez A, Gabriel K, Nehme EK, Mandell DJ, Hoelscher DM. Measuring the bias, precision, accuracy, and validity of self-reported height and weight in assessing overweight and obesity status among adolescents using a surveillance system. Int J Behav Nutr Phys Act. 2015;12(Suppl S1):S2. doi:10.1186/1479-5868-12-S1-S2
Vascular Health and Risk Management

\section{Publish your work in this journal}

Vascular Health and Risk Management is an international, peerreviewed journal of therapeutics and risk management, focusing on concise rapid reporting of clinical studies on the processes involved in the maintenance of vascular health; the monitoring, prevention and treatment of vascular disease and its sequelae; and the involvement

\section{Dovepress}

of metabolic disorders, particularly diabetes. This journal is indexed on PubMed Central and MedLine. The manuscript management system is completely online and includes a very quick and fair peerreview system, which is all easy to use. Visit http://www.dovepress. com/testimonials.php to read real quotes from published authors. 